\title{
ANALYSIS OF FIBER ORIENTATION IN THE WOOD-POLYMER COMPOSITES (WPC) ON SELECTED EXAMPLES
}

\author{
Wiesław Frącz' ${ }^{1}$ Grzegorz Janowski ${ }^{1}$ \\ 1 Rzeszow University of Technology, Department of Materials Forming and Processing, 8 Powstańców \\ Warszawy Ave., 35-959 Rzeszów, Poland, e-mail: wf@prz.edu.pl, gjan@prz.edu.pl
}

Received: 2017.05.15

Accepted: 2017.08.01

Published: 2017.09.03

\begin{abstract}
The fibers orientation in the polymer matrix is an important factor determining mechanical properties of products made of composites by means of an injection molding process. The fibers arrangement has an effect on shrinkage of the composite and the dimensional accuracy of molded piece. The knowledge of fiber orientation can determine the proper dimensions and design of the molding cavities and then correct some of physical and mechanical properties of the molded piece. The orientation of fillers depends on many factors, among which the important role play processing parameters including the injection speed. The aim of this study was to assess the orientation of the fibers in wood-polymer composite on the selected examples. The knowledge and proper use of micromechanical models allow to evaluate the fibers flow and their orientation in polymer matrix. The research was performed both for numerical simulations and experimental studies for results verification.
\end{abstract}

Keywords: fibers orientation, injection molding, numerical simulations, wood-polymer composites.

\section{INTRODUCTION}

The use of petroleum resources, an increase of its prices, problems of plastic waste, and thus their impact on the environment, make it necessary to limit the consumption of synthetic polymers and the use of modern, more easily biodegradable materials such as wood-polymer composites (WPC) [2].

The combined aesthetics of wood with the durability of the polymer, relatively good mechanical properties and improved physicochemical properties can make it an attractive product compared with standard polymer without filler. The world's polymer composites containing wood as a filler, in English-language are defined as Wood Plastic Composites (WPC). In definition, WPC composites are materials which comprise a polymer and (in addition) wood fiber or wood flour, and also the auxiliaries materials in differ- ent proportions [10]. In many cases, depending on the polymer matrix, they can be processed as thermoplastics. Polymer matrix filled with wood flour or fiber exhibit favorable mechanical properties, greater rigidity, lower water absorption, die swelling and lower linear shrinkage $[4,15,16$, 18]. WPC composites pose no threat to the environment in the course of treatment and recycling processes [3, 13]. Furthermore, after an appropriate modification, they are partially biodegradable [12]. These are promising materials that can be used in industries such as: automotive, construction, furniture, and household appliances [11].

One of the most important aspects of fiberreinforced composites processing is to know the orientation of fibers. The fibers orientation is the primary factor affecting the mechanical properties of composites $[5,6]$. In the most effective structure the fibers are unidirectionally aligned. In order to predict the mechanical properties of 
molded piece, it is necessary to simulate the filling process of the fiber reinforced plastic and an analysis of fiber orientation [4].

The aim of this study was to assess the orientation of the fibers in wood-polymer composite (WPC) on the selected examples. Knowledge and proper use of mathematical models in the field of micromechanics allow to evaluate the flow of fibers and their orientation at its polymer matrix. The research was performed both for numerical simulations and experimental studies in order to verify the results.

\section{THE FIBERS ORIENTATION CALCULATIONS}

The three-dimensional orientation of fibers in a polymer matrix describes the tensor of the second order (1) [1]. Graphical presentation of the calculated values and eigenvectors of the tensor orientation are presented by equation (1)

$$
a_{i j}=\left[\begin{array}{lll}
a_{11} & a_{12} & a_{13} \\
a_{21} & a_{22} & a_{23} \\
a_{31} & a_{32} & a_{33}
\end{array}\right] \rightarrow\left[\begin{array}{ccc}
\lambda_{1} & 0 & 0 \\
0 & \lambda_{2} & 0 \\
0 & 0 & \lambda_{3}
\end{array}\right] ;\left[\begin{array}{lll}
e_{1} & e_{2} & e_{3}
\end{array}\right]
$$

The initial nine tensor components are reduced to five independent components, where: $\mathrm{a}_{11}+\mathrm{a}_{22}+\mathrm{a}_{33}=1$.

Fibers orientation defines the three main components of the tensor:

- $\mathrm{a}_{11}$ - the fibers orientation along the flow direction $(0-1)$,

- $\mathrm{a}_{22}$ - the fibers orientation in transverse direction to the flow direction $(0-1)$,

- $\mathrm{a}_{33}$ - the fibers orientation slope in 1-3 plane (-0.5 - 0.5),

The eigenvectors indicate the basic conditions of fibers arrangement while eigenvalues give the statistical proportions ( 0 to 1$)$ of the fibers location with respect to their direction. This information is used to determine the ellipsoid orientation which defines the arrangement of the fiber. The ellipsoid is the basic model describing the shape of inclusions. The general orientation of the ellipsoid is shown in Fig. 1.

To evaluate the fibers orientation in a polymer matrix the Tucker-Folgar model is applied [17]:

$$
\frac{D a_{i j}}{d t}=-\frac{1}{2}\left(\omega_{i k} a_{k j}-a_{i k} \omega_{k j}\right)+\frac{1}{2} \lambda\left(\dot{\gamma}_{i k} a_{k j}+a_{i k} \gamma_{k j}-2 a_{i j k \gamma_{i j}}\right)+2 C_{1} \gamma\left(\delta_{i j}-3 a_{i j}\right)
$$

where: $\mathrm{a}_{\mathrm{ji}}$ - fiber orientation tensor, $\mathrm{w}_{\mathrm{ij}}$ - vorticity tensor, $\gamma_{\mathrm{ij}}$ - strain rate tensor, $\mathrm{C}_{1}$ - interaction coefficient fibers.

Elastic properties of composites are mostly calculated based on the Halpin-Tsai micromechanical model [8]:

$$
\frac{\mathrm{P}}{\mathrm{P}_{\mathrm{m}}}=\frac{1+\zeta \eta \mathrm{V}_{\mathrm{f}}}{1-\zeta \mathrm{V}_{\mathrm{f}}}
$$

wherein:

$$
\eta=\frac{\frac{P_{f}}{P_{m}}-1}{\frac{P_{f}}{P_{m}}+1}
$$

where: $\mathrm{P}$ - appropriate modules of the composite (shown in Table $1[8]$ ), $\mathrm{P}_{\mathrm{f}}, \mathrm{P}_{\mathrm{m}}$ - respectively, the modules for the fiber and matrix, $\zeta$ - parameter depends on the composite characteristics, $\mathrm{V}$ - the volume fraction of fibers in the polymer matrix, $\mathrm{f}$ - index that specifies a reference to the fiber, $m$ - index that specifies a reference to the matrix.

Moreover, in order to determine coefficients of thermal expansion the Rosen-Hashin model was applied [14].

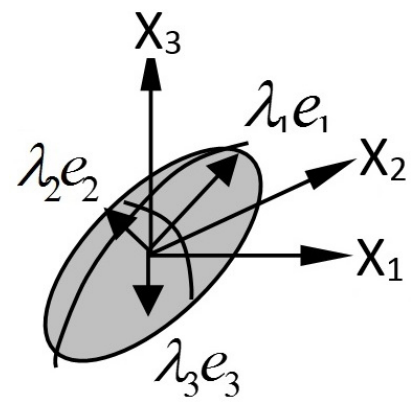

Fig. 1. The general arrangement of ellipsoid fiber orientation

In this study the flow of polymer (polypropylene) reinforced with wood fibers was analyzed. The basic properties of wood fibers, necessary for carrying out the simulation are presented in Table 2.

An interesting issue is the possibility of analyzing the fiber orientation using the computer image analysis, such as the Sobel operator procedure. The Sobel operator was the algorithm used for edges detection of fibers during digital image processing. Practically, this operator turns out 
Table 1. The parameters of the Halpin-Tsai model [8]

\begin{tabular}{|c|c|c|c|c|}
\hline$E_{11}$ & $E_{f}$ & $E_{m}$ & $2(I / d)$ & Longitudinal modulus \\
\hline$E_{22}$ & $E_{f}$ & $E_{m}$ & 2 & Transverse modulus \\
\hline$G_{12}$ & $G_{f}$ & $G_{m}$ & 1 & Longitudinal shear modulus \\
\hline
\end{tabular}

to linear filtering using a matrix of $\Delta \mathrm{V}$ to detect vertical edges and $\Delta \mathrm{H}$ to detect horizontal edges. The matrices are presented by the equation (5). The detection of both types of edges consists of the sum of two results. The result of filtering was changed to the binary form - for each pixel the intensity from 0 to 1 was assigned [9].

$$
\Delta \mathrm{V}=\left[\begin{array}{ccc}
1 & 2 & 1 \\
0 & 0 & 0 \\
-1 & -2 & -1
\end{array}\right], \Delta \mathrm{H}=\left[\begin{array}{ccc}
-1 & 0 & 1 \\
-2 & 0 & 2 \\
-1 & 0 & 1
\end{array}\right]
$$

\section{THE NUMERICAL SIMULATIONS}

The basic stages of simulation preparation were: the preparing of molded piece of a geometrical model, the model discretization using tetra finite elements (FE), the setting up of initial and boundary conditions, the numerical calculations and results interpretation. The molded part was designed by means of NX8 software (Fig. 2a). In the numerical model of injection mould the filling and cooling systems were taken into account (Fig. 2b). Numerical simulations were performed using the Autodesk Moldflow Insight 2013 commercial code.

The use of 3D numerical model of the molded piece allowed to make a more accurate analysis of phenomena occurring during manufacturing [7]. The key stage before simulations was the setting up of composite properties. These data included
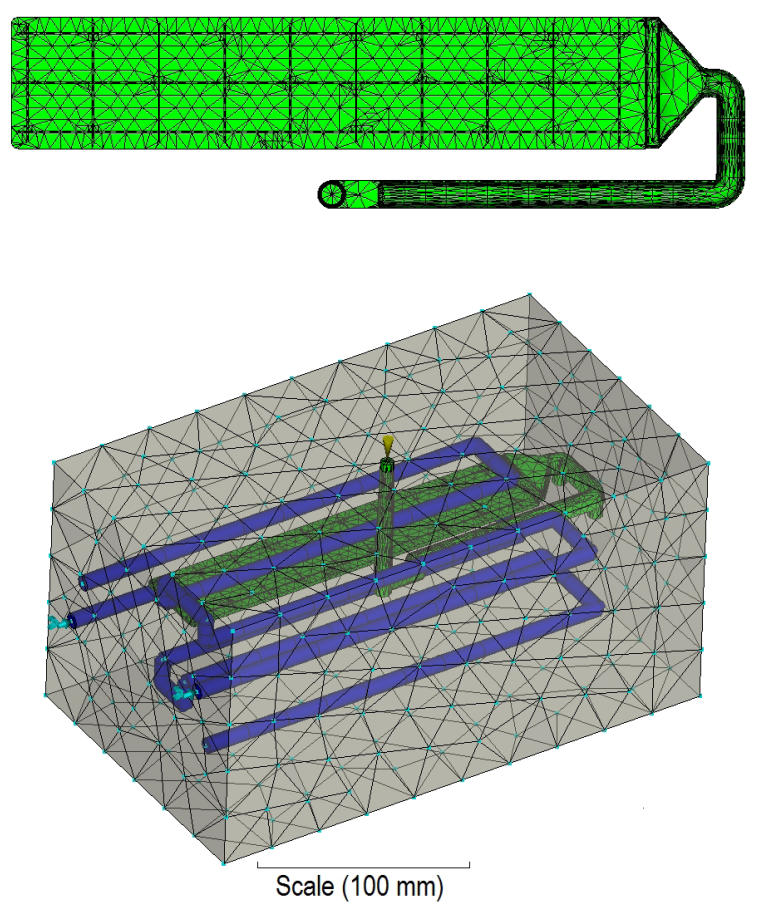

Fig. 2. The numerical models:

a) of the cavity (146693 FE of tetrahedral type),

b) of the injection mold

the thermal, rheological and mechanical properties. Simulations were performed for the same processing parameters as during experiment, i.e. melt temperature $-200^{\circ} \mathrm{C}$, mold temperature $40^{\circ} \mathrm{C}$, packing time $-10 \mathrm{~s}$. The injection speed was a variable parameter. The manufacturing process of the molded piece was simulated using processing parameters at which plastic flow was difficult (very low injection speeds) and conversely, at which the flow was easier due to the low polymer viscosity (very high injection speeds).

Table 2. The properties of wood fibers

\begin{tabular}{|c|c|c|}
\hline density & $\mathrm{kg} / \mathrm{m}^{3}$ & 2000 \\
\hline specific heat & $\mathrm{J} /\left(\mathrm{kg}^{\circ} \mathrm{C}\right)$ & 1000 \\
\hline thermal conductivity & $\mathrm{W} /\left(\mathrm{m}^{\circ} \mathrm{C}\right)$ & 1 \\
\hline modulus of elasticity $-\mathrm{E}_{1}$ direction & $\mathrm{MPa}$ & 10000 \\
\hline modulus of elasticity $-\mathrm{E}_{2}$ direction & $\mathrm{MPa}$ & 10000 \\
\hline Poisson's ratio $-\mathrm{v}_{12}$ direction & - & 0.3 \\
\hline Poisson's ratio $-\mathrm{v}_{23}$ direction & - & 0.3 \\
\hline shear modulus - $\mathrm{G}_{12}$ direction & $\mathrm{MPa}$ & 3846 \\
\hline thermal expansion $\alpha_{1}$ & $1 /{ }^{\circ} \mathrm{C}$ & $1 * 10^{-5}$ \\
\hline thermal expansion $\alpha_{2}$ & $1 /{ }^{\circ} \mathrm{C}$ & $1 * 10^{-5}$ \\
\hline tensile strength - parallel to the main axis of the fiber & $\mathrm{MPa}$ & 10000 \\
\hline tensile strength - perpendicularly to the main axis of the fiber & $\mathrm{MPa}$ & 10000 \\
\hline I/d fibers & - & 10 \\
\hline
\end{tabular}


Fiber orientation tensor

$=0.7571$

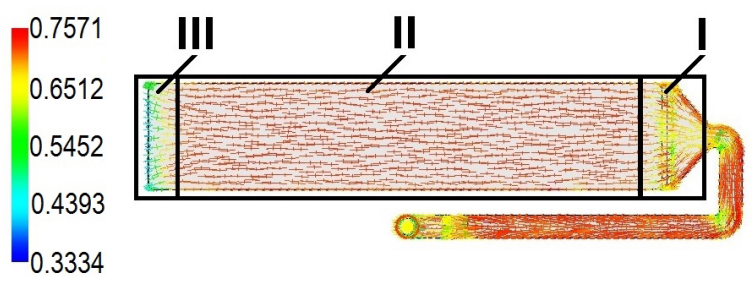

Fig. 3. The fibers orientation in the final stage of polymer flow at $1000 \mathrm{~cm}^{3} / \mathrm{s}$ based on numerical simulation using the Moldflow MPI software

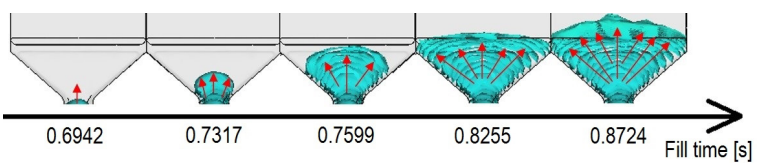

Fig. 4. The filling stages in the cavity zone I

The results obtained on the basis of fibers orientation analysis were treated as the probability of the fibers arrangement in the main direction, coinciding the flow direction of the composite. The high probability of the fibers orientation in the main flow direction determines the suitable component of tensor orientation close to value of 1 , if the probability is small the suitable tensor component has a value close to 0 .

The fibers orientation analysis was carried out on the basis of mold cavity filling steps and the flow vectors. It was assumed the $\mathrm{L} / \mathrm{D}=10$ aspect ratio on the base of microscopic measurements of fibers length mean values to their diameter. The Tucker - Folgar model was used to calculate the fibers orientation. The elastic properties of the short fiber reinforced composites were calculated

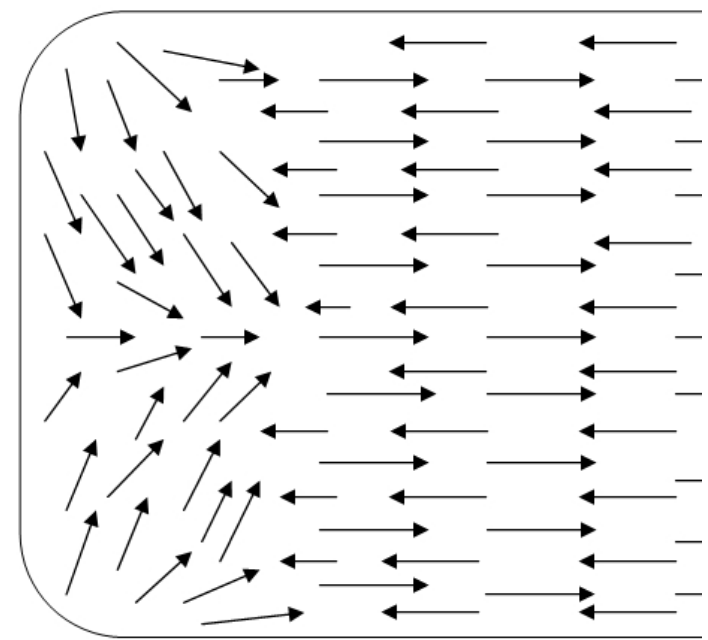

Fig. 5. The velocity vectors of polymer in zone III of analysed specimen

based on the Halpin-Tsai micromechanical model. The elastic properties of the polymer matrix and fibers, and also the fibers content and their shape were included. In order to determine the longitudinal and transverse coefficients of thermal expansion the Rosen-Hashin model was selected. In order to approximate the fiber orientation tensor of the fourth order with respect to the tensor of second order, the Rosen-Hashin model was used too.

For easier results interpretation the model of the molded piece was divided into three zones. Some selected areas and the results of the fibers orientation were shown in Fig. 3. The first zone is characterized by low value of fiber orientation tensor. This means that in this phase fibers are not uniformly oriented. This is caused by uneven filling of the mold cavity.

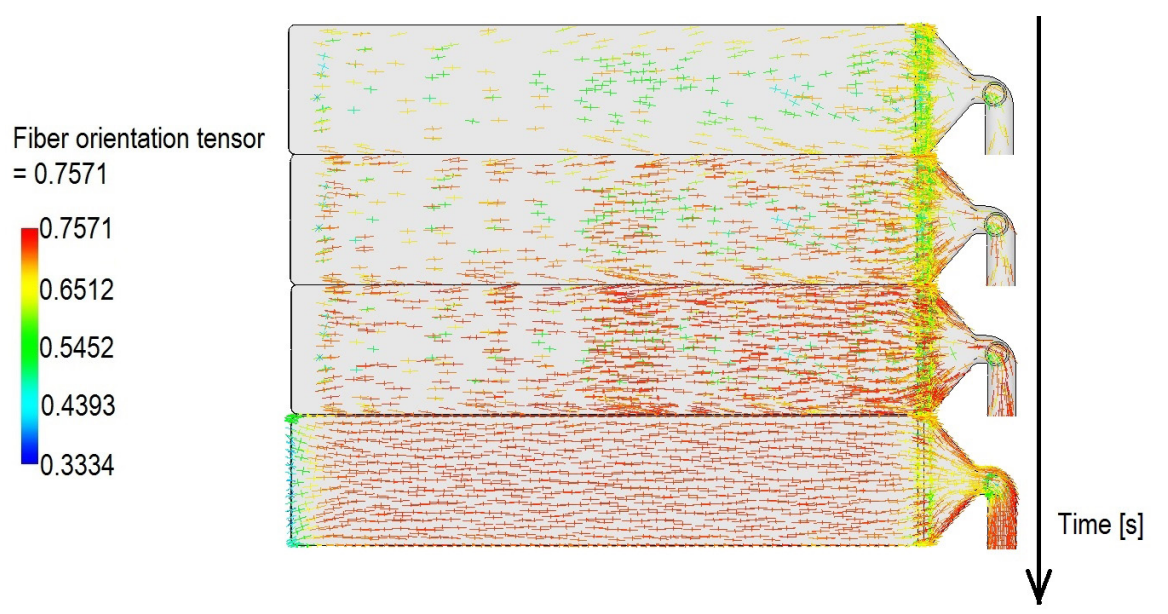

Fig. 6. The fibers orientation change during injection cycle by flow rate of $1000 \mathrm{~cm}^{3} / \mathrm{s}$ 


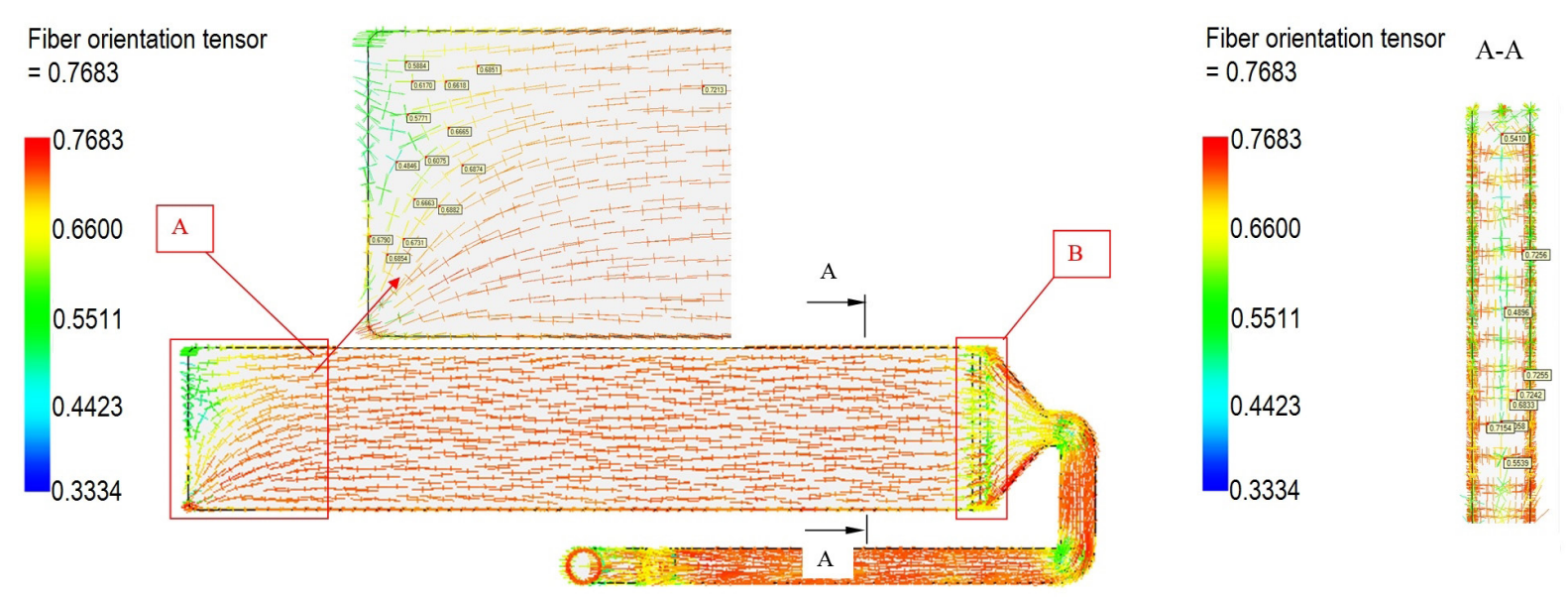

Fig. 7. The dominant fibers orientation at the end of packing phase for the flow rate of $20 \mathrm{~cm}^{3} / \mathrm{s}$

Moreover, the sequential steps of mold cavity filling were examined (Fig. 4) to predict the fibers behavior in polymer matrix. In the initial phase the polymer expands in a cavity. And then the flow becomes targeted, which is evident in the final areas of zone I. The second molding area has the highest value of the fiber orientation tensor. The polymer flows in this section uniformly along the molded piece. This results in uniform orientation of the fibers in the entire zone. In the third zone the fiber orientation ratio value is lower than in the area of the second or even the first one. The fibers orientation in the third zone coincides with the velocity vectors (Fig. 5). The fibers orientation changes the entire length of cavity during injection cycle for a constant flow rate of $1000 \mathrm{~cm}^{3} / \mathrm{s}$ are shown in Fig. 6 .

The fibers orientation at the end of the packing phase for a flow rate of $20 \mathrm{~cm}^{3} / \mathrm{s}$ is shown in Fig. 7. The distorted orientation of fibers in the areas A and B was shown. The simulation results were confirmed by the experiment. The fibers orientation ratio in this area indicate the lack of a strong fibers orientation in the flow direction.

Fig. 8 presents the results of simulations for the flow rate of 20 and $100 \mathrm{~cm}^{3} / \mathrm{s}$ (corresponding to the experimental research) and for the hypothetical value of $1000 \mathrm{~cm}^{3} / \mathrm{s}$ in the area $A$ of the molded piece. It may be noted that the fiber orientation tensor depends on the injection speed too.

\section{THE EXPERIMENTAL STUDY}

The Moplen HP 648T polypropylene made by Basell Orlen Polyolefins company was used as the polymer matrix to produce the WPC. As the filler the wood fibers (20\%) manufactured by
JRS - J. RETTENMAIER \& Söhne Company (trade name: Lignocel C120) was used. To manufacture the composite the adhesion promoter of P613 type with MFR $=49 \mathrm{~g} / 10 \mathrm{~min}$ was used. The bulk density of composite components were as follows: the wood fiber $-167 \mathrm{~kg} / \mathrm{m}^{3}$ the PP $565 \mathrm{~kg} / \mathrm{m}^{3}$.

The WPC composite was prepared using EHP 25 extruder, made by Zamak Mercator company, equipped with a cooling bath and

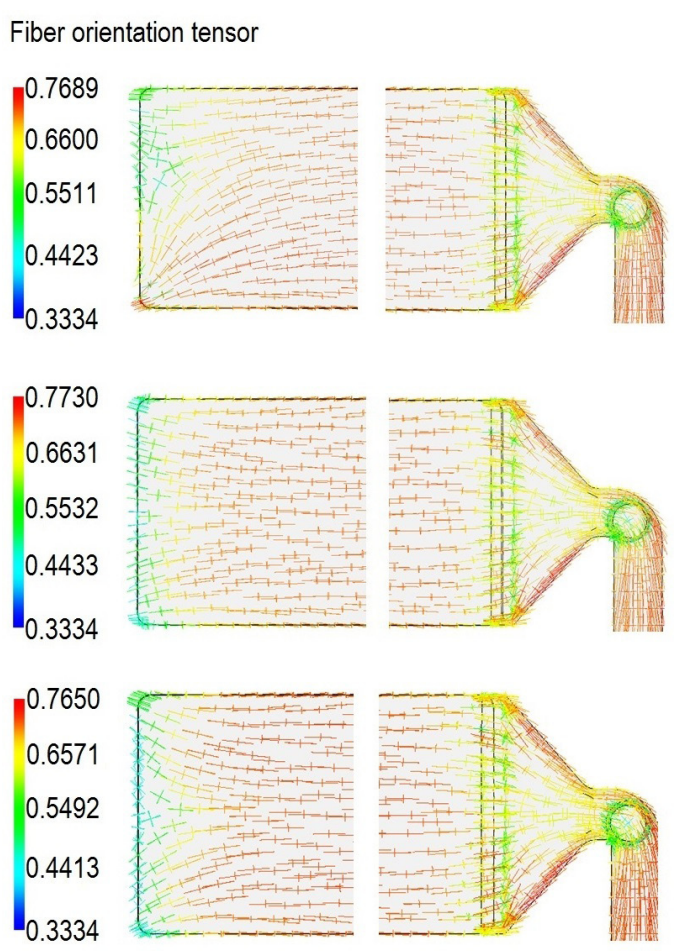

Fig. 8. Comparison of the dominant fiber orientation in zones $A$ and $B$ with the flow rate of: a) $20 \mathrm{~cm}^{3} / \mathrm{s}$, b) $100 \mathrm{~cm}^{3} / \mathrm{s}, \mathrm{c}$ ) in $1000 \mathrm{~cm}^{3} / \mathrm{s}$ 


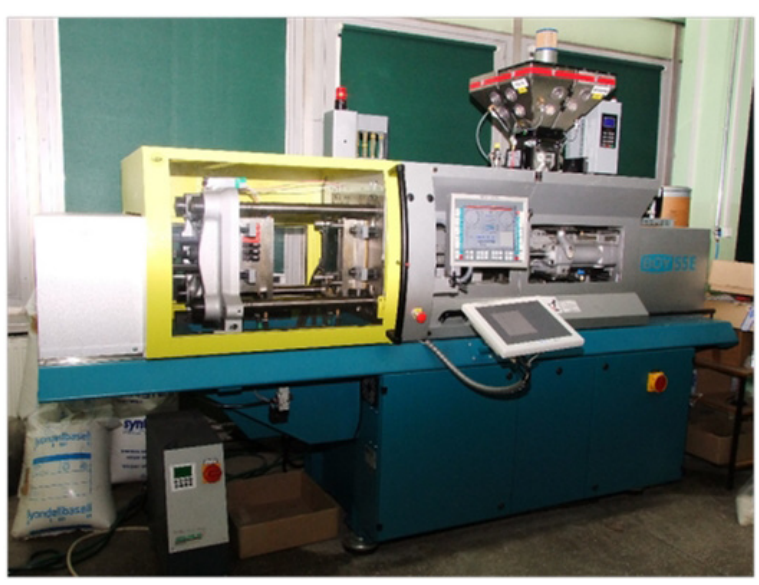

Fig. 9. The Dr Boy 55E injection molding machine

granulator. During the extrusion process the adjustable parameters were used: the zones temperatures: $180,175,170$ and $140^{\circ} \mathrm{C}$, screw rotation of $10 \mathrm{~min}^{-1}$. Prior to extrusion process the wood fibers were dried in the dryer at $100^{\circ} \mathrm{C}$ for approx. 4 hours.

To prepare the test samples the Dr Boy 55E injection molding machine was used (Fig. 9). Before the injection molding process the WPC pellets were dried at $100^{\circ} \mathrm{C}$ for 2 hours. Then the pellets were injected at different injection speeds, which correspond to the flow rate of 20 and $100 \mathrm{~cm}^{3} / \mathrm{s}$, respectively.

In order to perform the experimental studies the single-cavity injection mold with removable insert (the cavity thickness of $2 \mathrm{~mm}$ ) was used (Fig. 10). The total length of the cavity with a constant rectangular cross-section $(40 \times 2 \mathrm{~mm})$ was $195 \mathrm{~mm}$. Runner system consisted of a conical sprue (the length of $80 \mathrm{~mm}$ and the minor diameter of $6 \mathrm{~mm}$ ), the runner diameter of $8.5 \mathrm{~mm}$ and gap gate. The mold has two circuits cooling channels with a diameter of $8 \mathrm{~mm}$. Three pressure and temperature sensors were placed in the cavity, at distance $80 \mathrm{~mm}$ from each other. The first sensor was mounted at the distance of 17.5 smm from the gate.

To measure the pressure the piezoelectric sensors of 6002B type (made by Priamus company) were used. To register the pressure during the injection cycle the four-channel amplifier of Priased 5080 type with computer software was used. In the presented research the pressure drop between two initial sensors was recorded. The plastic temperature in the mold cavity was measured near of the first pressure sensor by means of N-type thermocouple. The tempera-
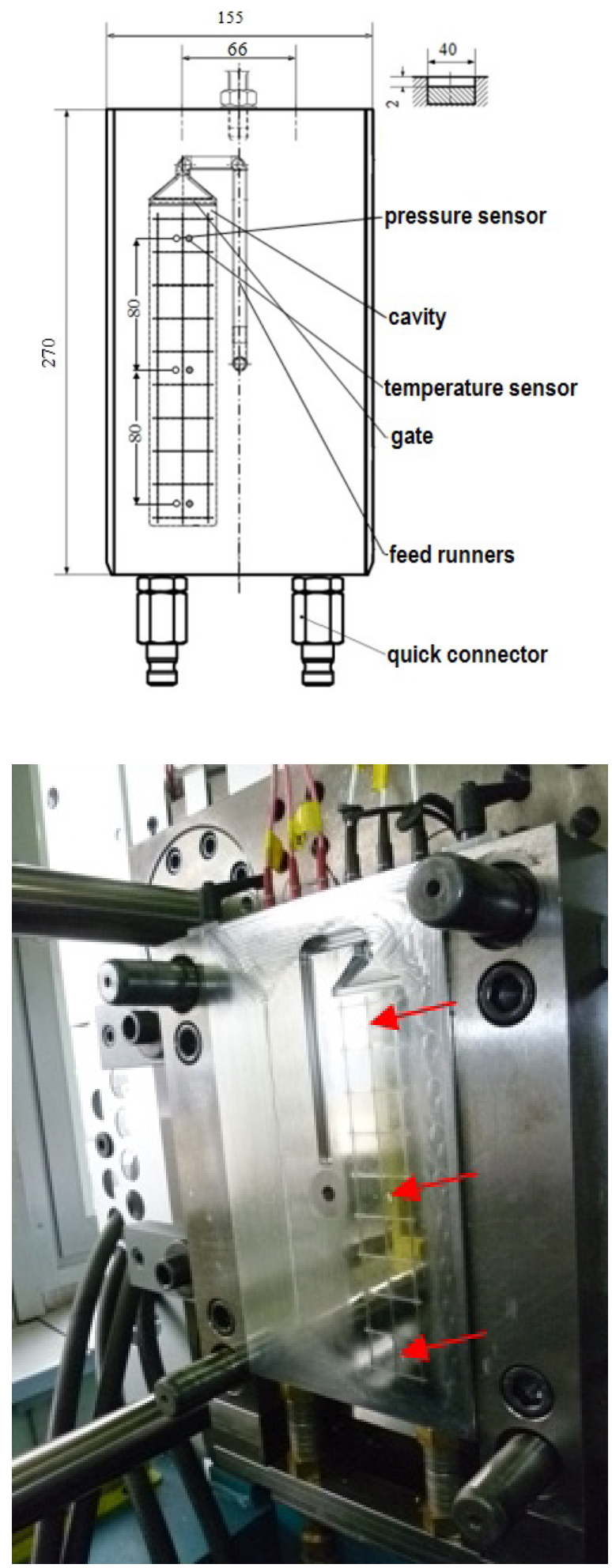

Fig. 10. The single-cavity injection mold with pressure and temperature sensors: a mold insert (above), places, where sensors are mounted in the injection mold (below)

ture measurement was made in the middle of the cavity thickness. The pressure and temperature measurement in the mold cavity was used to verify the calculated plastic parameters. 


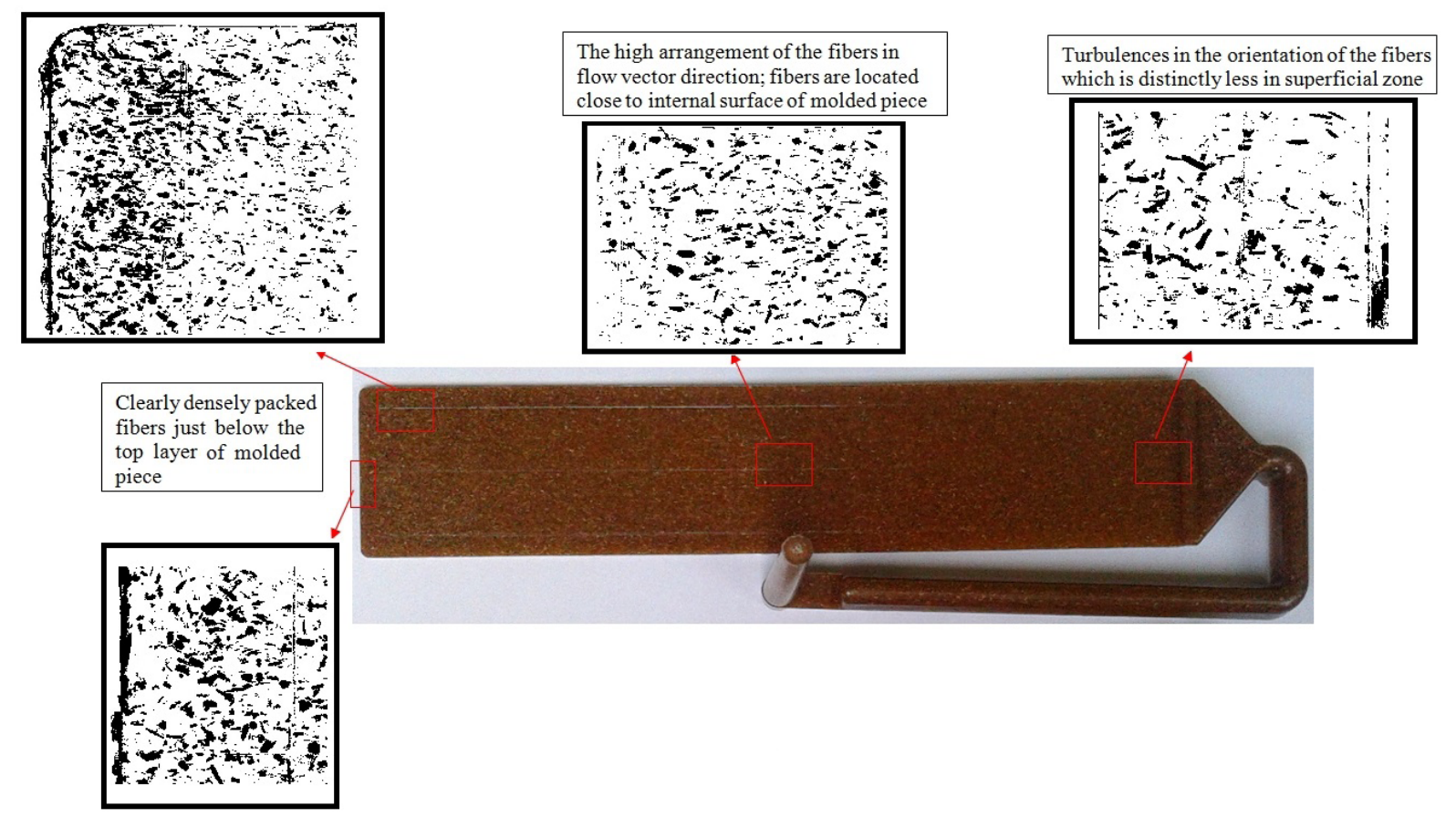

Fig. 11. The fibers arrangement in selected areas of molded piece for the flow rate of $20 \mathrm{~cm}^{3} / \mathrm{s}$

\section{THE FIBER ORIENTATION ANALYSIS}

In presented study the analysis of fiber orientation for molded sample was carried out. The prepared samples were analyzed using the LV100D NIS type of Nikon microscope and images software including the Sobel Operator transformation (Fig. 11).

The pictures of visible fiber orientation made by means of a microscope were converted using the Sobel Operator procedure. Transformation was made using the Adobe Photoshop software. The fibers disorientation took place in the initial and final molded zones (see: zones I and III in Fig. 3). This is due to the pressure influence and cavity geometry change in these places. In the middle zone (zone II, Fig. 3), the flow is steady, which causes high fibers arrangement along flow direction vector.

\section{CONCLUSIONS}

The performed tests and simulations allowed to formulate the following conclusions:

- The fiber orientation in composites which changes the directional properties of molded piece depends on injection speed. The high compatibility between the fibers orientation from the experimental and numerical study was received. The higher the injection speed, the greater the orientation of the fibers in the direction of the velocity vectors, but it depends on areas of molded piece too.

- The high values of the dominant fibers orientation obtained as simulation results $(0.8$ value of fiber orientation tensor ratio) indicate a high probability of their orientation in a given direction. Higher values of the fiber orientation tensor ratio can provide higher strength properties of molded part in direction of fiber orientation.

- The fibers orientation is also changed with injection phase. Their final arrangement depends on the area of the part. Disorders of the fibers are related to the pressure change and changes in geometry of cavity (runner bends, gate areas - III zone of molded piece). This was confirmed by photographs of molded piece surface.

\section{Acknowledgements}

The research leading to these results has received funding from the People Programme (Marie Curie International Research Staff Exchange) of the European Union's Seventh Framework Programme FP7/2007-2013/ under REA grant agreement No. PIRSESGA-2013-610547. 


\section{REFERENCES}

1. Advani S.G. and Tucker III C.L. The use of tensors to describe and predict fiber orientation in short fiber composites. Journal of Rheology, 31(8), 1987, 751-784.

2. Ashori A. Wood-plastic composites as promising green-composites for automotive industries. Bioresource Technology, 99(11), 2008, 4661-4667.

3. Ashori A. and Nourbakhsh A. Characteristics of wood-fiber plastic composites made of recycled materials. Waste Management, 29(4), 2009, 1291-1295.

4. Bednarz A., Frącz W. and Janowski G. The use of image analysis in evaluation of the fibers orientation in Wood-polymer composites (WPC). Open Engineering, 6(1), 2016, 737-741.

5. Bouafif H., Koubaa A., Perre P. and Cloutier A. Effects of fiber characteristics on the physical and mechanical properties of wood plastic composites. Composites Part A: Applied Science and Manufacturing, 40(12), 2009, 1975-1981.

6. Frącz W. and Janowski G. Strength analysis of molded pieces produced from wood-polymer composites (WPC) including their complex structures. Composites theory and practice, 16(4), 2016, 260-265.

7. Gajdos I., Duleba B., Spisak E., Greskovic F. and Dulebova L. Optimization of injection molding process by DOE. Hutnik - Wiadomości Hutnicze, 81(7), 2014, 470-475.

8. Halpin J.C. and Kardos J.L. The Halpin-Tsai Equations: A review. Polymer Engineering \& Science, 16(5), 1976, 345-352.

9. Kim E.G., Park J.K. and Jo S.H. A study on fiber orientation during the injection molding of fiber- -reinforced polymeric composites (comparison between image processing results and numerical simulation). Journal of Materials Processing Technology, 111(1), 2001, 225-232.

10. Kim J.K. and Pal K. Recent advances in the processing of wood-plastic composites. Springer Science \& Business Media, 2010.

11. Klyosov A.A. Wood -plastic composites. Wiley interscience, 2007.

12. La Mantia F.P. and Morreale M. Green composites: A brief review. Composites Part A: Applied Science and Manufacturing, 42(6), 2011, 579-588.

13. Petchwattana N., Covavisaruch S. and Sanetuntikul J. Recycling of wood-plastic composites prepared from poly (vinyl chloride) and wood flour. Construction and Building Materials, 28(1), 2012, 557-560.

14. Rosen B.W. and Hashin Z. Effective thermal expansion coefficients and specific heats of composite materials. International Journal of Engineering Science, 8(2), 1970, 157-161.

15. Salemane M.G. and Luyt A.S. Thermal and mechanical properties of polypropylene-wood powder composites. Journal of Applied Polymer Science, 100(5), 2006, 4173-4180.

16. Stokke D.D., Wu Q. and Han G. Introduction to wood and natural fiber composites, John Wiley \& Sons, 2013.

17. Tucker III C.L. and Liang E. Stiffness prediction for unidirectional short-fiber composites: Review and evaluation. Composites Science and Technology, 59(5), 1999, 655-671.

18. Wechsler A. and Hiziroglu S. Some of the properties of wood-plastic composites. Building and Environment, 42(7), 2007, 2637-2644. 